\section{A CASE OF DWARFISM.}

BY

A. A. JUBB, M.D., B.Sc.Pub.Hzalth,

SCHOOL MEDICAL INEPECTOR, WEST RIDING COUNTY COUNCIL.

H. W., a schoolboy, is aged 9, his height is $36 \frac{1}{2}$ in., and his weight in clothes $38 \mathrm{lb}$. The photographs exhibit the following features, which are present in more or less degree: The large head, the depressed nose, prognathism, and the pendulous abdomen with lordosis, and the decentralization of the body. In the profile pictare a divergence of the middle and ring fingers of the hand can be seen, though they were pressed together to avoid exaggeration.

The hamerus messures $4 \frac{1}{2}$ in. and the clavicle 4 in. The skall is 21 in. in circumference, and is markedly protaberant in the frontal and parietal regions. The palate is very narrow, the superior alveolus thick, the teeth irregular and decayed, and mouth. breathing is present. The skin is smooth and supple, and fat is abundant in the lower half of the body. There is a slight con. vergent strabismus, and a small ingainal hernia was present at one time. The centre of the body is above the umbilious at a point nearly one-third of the distance to the xiphoid. The principal joints are enlarged, bat there is only a faint rachitic rosary. The face is pale and the expression vacuous, still the boy is physically active though not quite up to the average in intelligence. Sexual development is unimpaired.

The family history is uneventfal. The boy is the second of five children, and his mother says he was "like the others" when born, but his teeth came late, he did not walk till the age of 3 , and he was treated for "rickets and water in the head." When he was 4 years old she noticed that he had acquired a habit of scratching his head with his foot. He can easily put his toes into his mouth without bending the knee. The obvious shortening of the upper segments of the arms and legs might suggest a taint of achondroplasia, but against this some particulars may be noted : (1) Absence of congenital micro. melia; (2) disproportion between trunk and limbs is only slight, the fingers fall below the level of the great trochanter; (3) though there is a fork between the middle and ring fingere, the main en trident is not present; (4) the skall is not vaulted but bossed; (5) the decentralization of the body is due to the size of the skull, not to shortness of the legs.

The deformity is no doubt due to infantilism and rickets. The rickets has affected the skull and joints ; the infantilism, which may affect different parte, and even single organs at different times, has involved the sexual developmont not at all, and the mental faculties only to a slight extent. Its chief effect is seen in the infantile moulding of the trunk and limbs. The conjunction of rickets and a mild degree of hydrocephalus suggests that congenital syphilis has been the cause of the infantilism.

\section{fftenturanda:}

\section{MEDICAL, SURGICAL, OBSTETRICAL.}

RHUBARB POISONING.

I RECEIVED an urgent call to see a man who was stated to be suffering from a severe attack of diarrhoea. The patient was lying supine in bed when I entered the room. The eyes were closed; the face extremely pale and bathed in perspiration; the extremities cold ; the fingers and ears slightly cyanosed; the respiration rapid and shallow; he could only be roused with diffculty; the pulse was 140 , regular, very feeble. A hypodermic injection of ether soon restored consciousness with improved circulation, and he was able to answer questions. He stated that, with the exception of slight lumbar ache, he was quite free from pain. He complained, however, of a little numbness in the extremities. He had not vomited, and had no feeling of nausea and no headache. He had no flatulence nor eructations. He said that the pain which preceded and accompanied the action of the bowels was of a griping character, had come on suddenly, and was so severe that he almost fainted. He had three watery stools which were expelled with violence. These were followed, after an interval of half an hour, by two actions of the same kind at an interval of a fow minutes. After this he felt so exhausted that he retired to bed. Rhubarb had always acted upon him as a purgative, and two years before it had caused a similar attack to that from which he was now suffering, but of not so severe a nature. On that occasion he had vomited before the action of the bowels. On the present occasion the rhubarb had been cooked in the same way (stewed). His wife, who had partaken freely of the rhubarb on both occasions, was not affected thereby.

On examination the mouth temperature was $97.8^{\circ}$ F., the tongue was clean and the breath not offensive. On removing the bedclothes it was noticed that he had passed a small motion into the bed. The abdomen was not distended, but was resistant to pressure, and was tender over the entire surface, but more markedly over the hypogastrium. The lumbar pain was distinctly increased during bimanual palpation of the kidneys.

The patient was ordered to remain in bed for twentyfour hours; and to keep strictly to milk diet during that time; each portion of milk to be mixed with an equal quantity of lime water.

When seen five hours later the paranaesthesia of the limbs had completely cleared up, but the loin pain had slightly increased. A few ounces of high-coloured urine had been collected, and this, after standing, deposited, along with many uric acid crystals, a considerable number of small, transparent, calcium-oxalate crystals. The latter were also found in the urine passed the following morning, but not subsequently. There was an uneventful recovery.

In another case the patient-a healthy man of 36 yearshad partaken freely of stewed rhubarb, which, with the exception of the paranaesthesia, had given rise to symptoms similar to those which occurred in the first case. On this patient also rhubarb had generally acted as a purgative.

Garden rhubarb (Rheum rhaponticum) - of which there are several varieties-is rightly regarded as a wholesome food and an excellent substitute for fruit. Since 1573, when it was first introduced into this country from Russia, the young leaves were used, and continued to be used, as a vegetable until the end of the eighteenth century. That it does not agree with every one is, it would appear, evident from its effect in the two cases above mentioned; and also-and with startling emphasis-in that of the patient whose death from its use formed the subject of a coroner's inquest at Catford some weeks since, as reported in the daily papers.

As to the precise nature of the agent responsible for the toxic action of rhubarb on some organisms, I possess no knowledge. It would seem probable that the presence of oxalates in the urine and the severe intestinal irritation 